OPEN ACCESS

Edited by:

Giovanni Nigita,

The Ohio State University,

United States

Reviewed by:

Gioacchino Paolo Marceca,

University of Catania, Italy

Abhijit Shukla,

Memorial Sloan Kettering Cancer

Center, United States

Natalia Pinello,

Centenary Institute of Cancer

Medicine and Cell Biology, Australia

${ }^{*}$ Correspondence:

Tao Xu

xutao0101@yeah.net

Kai Sun

1085844308@qq.com

Specialty section:

This article was submitted to Epigenomics and Epigenetics, a section of the journal Frontiers in Cell and Developmental Biology

Received: 22 February 2021 Accepted: 10 May 2021

Published: 04 June 2021

Citation:

Luo J, Xu T and Sun K (2021) N6-Methyladenosine RNA Modification in Inflammation: Roles, Mechanisms, and Applications. Front. Cell Dev. Biol. 9:670711. doi: 10.3389/fcell.2021.670711

\section{N6-Methyladenosine RNA Modification in Inflammation: Roles, Mechanisms, and Applications}

\author{
Jiahui Luo', Tao Xü ${ }^{2 *}$ and Kai Sun ${ }^{3 *}$ \\ 1 The Center for Biomedical Research, Tongji Hospital, Tongji Medical College, Huazhong University of Science and \\ Technology, Wuhan, China, ${ }^{2}$ Department of Rehabilitation, Tongji Hospital, Tongji Medical College, Huazhong University \\ of Science and Technology, Wuhan, China, ${ }^{3}$ Department of Orthopedics, Tongji Hospital, Tongji Medical College, Huazhong \\ University of Science and Technology, Wuhan, China
}

N6-methyladenosine (m6A) is the most prevalent internal mRNA modification. m6A can be installed by the methyltransferase complex and removed by demethylases, which are involved in regulating post-transcriptional expression of target genes. RNA methylation is linked to various inflammatory states, including autoimmunity, infection, metabolic disease, cancer, neurodegenerative diseases, heart diseases, and bone diseases. However, systematic knowledge of the relationship between m6A modification and inflammation in human diseases remains unclear. In this review, we will discuss the association between m6A modification and inflammatory response in diseases, especially the role, mechanisms, and potential clinical application of m6A as a biomarker and therapeutic target for inflammatory diseases.

Keywords: N6-methyladenosine, RNA modification, epigenetics, inflammation, inflammatory disease

\section{INTRODUCTION}

In recent years, epitranscriptomic modifications have been recognized as essential regulators of various physiological processes and disease progression. RNA modification is an example of dynamic epigenetic regulation. Early RNA modification studies have revealed important functions of RNA modification in translation and splicing. These studies focused on abundant non-coding RNAs, such as rRNA, tRNA, and small nuclear RNA (Jung and Goldman, 2018). The tRNA modification N1-methyladenosine (m1A) regulates the associations between tRNA and polysomes to stabilize tRNA tertiary structure and modify translation (Li et al., 2016). Pseudouridine ( $\Psi$ ) in snRNA participates in mRNA splicing, whereas $\Psi$ in rRNA ensures translational fidelity (Xiong et al., 2017).

N6-methyladenosine $(\mathrm{m} 6 \mathrm{~A})$ is the most prevalent internal mRNA modification, which was first discovered in the early 1970s (Dubin and Taylor, 1975). m6A participates in almost all processes involving mRNA metabolism, including RNA transcription, translation, and degradation (Roundtree et al., 2017a; Nachtergaele and He, 2018). Similar to DNA methylation, RNA m6A modification is a dynamic and reversible process (Zhao et al., 2020). m6A is installed by the methyltransferase complex (MTC) and removed by demethylases, which regulate the posttranscriptional expression of target genes (Batista, 2017; Dai et al., 2018). In molecular processing, $\mathrm{m} 6 \mathrm{~A}$ is involved in many steps of RNA metabolism, including pre-mRNA splicing, mRNA 
translation, nuclear export, mRNA degradation, and noncoding RNA biogenesis (Liu et al., 2017; Shi et al., 2017; Liu and Gregory, 2019).

Inflammation is a complex physiological reaction to microorganisms, autoimmunity, allergies, metabolism, and physical damage, all of which produce different types of inflammatory responses (Hawiger and Zienkiewicz, 2019). In acute inflammation, the initial response of the body to a stimulus is achieved by increasing white blood cell migration and plasma leakage from the blood to the site of injury (Bayarsaihan, 2011; Varela et al., 2018). Chronic inflammation progresses slowly, occurs for a longer duration, and can cause many diseases, including periodontal disease and diabetes (Dunning, 2009). Inflammatory response requires a complex regulatory network to achieve signal- and gene-specific levels of function (Medzhitov and Horng, 2009) for activating specific genes for antimicrobial defense, immune response, and tissue repair and remodeling (Medzhitov, 2008). Emerging evidence suggests that epigenetic modifications are involved in inflammatory response. Macrophages play critical roles in various inflammatory diseases, including obesity and arthritis. Chromatin modifications have been reported to participate in the regulation of macrophage phenotype (Nemat et al., 2009). In addition, DNA methylation and covalent histone modifications of transcription factors, including NF- $\mathrm{B}$ and the STAT families, have been found to modulate inflammatory genes (Medzhitov and Horng, 2009). However, the role of RNA modification in regulating inflammation and anti-inflammatory gene expression has only been recently elucidated. In this review, we will discuss the association between m6A methylation and inflammatory response in diseases, especially its role, mechanism, and potential clinical application in inflammation-related diseases.

\section{RNA m6A Methylation}

In mammals, approximately $0.1-0.4 \%$ of adenosine in mRNA is modified by $\mathrm{m} 6 \mathrm{~A}$, and each transcript has an average of 23 m6A modification sites (Desrosiers et al., 1974; Wei et al., 1975; Fu et al., 2014). m6A modifications are enriched in the $3^{\prime}$ untranslated regions (UTRs) near the stop codons of mRNA and within internal long exons, mainly with a consensus sequence of RRACH ( $\mathrm{R}=\mathrm{G}$ or $\mathrm{A} ; \mathrm{H}=\mathrm{A}, \mathrm{C}$, or $\mathrm{U}$ ) (Kane and Beemon, 1985; Dominissini et al., 2012). There are three types of regulators involved in m6A modifications and are referred to as "writers," "erasers," and "readers" (Figure 1).

"Writers" traditionally refer to a highly conserved mRNA methyltransferase complex that consists of methyltransferaselike 3 (METTL3), methyltransferase-like 14 (METTL14), and Wilms tumor suppressor-1-associated protein (WTAP) (Ping et al., 2014; Schwartz et al., 2014). Both METTL3 and METTL14 contain a S-adenosylmethionine-binding motif (Wang et al., 2016). METTL3 acts as a major catalytic component that modulates m6A modification (Barbieri et al., 2017). METTL14 is a pseudomethyltransferase that serves as an accessory component of METTL3 and participates in substrate recognition (Weng et al., 2018). They form a stable heterodimer and co-localize in nuclear speckles in a 1:1 ratio. WTAP is the main regulatory component and interacts directly with METTL3. It promotes methylation and ensures the nuclear location of the core writer complex (Liu et al., 2014; Schöller et al., 2018). The other known writers are methyltransferase-like 16 (METTL16) (Pendleton et al., 2017; Warda et al., 2017), KIAA1429 (Schwartz et al., 2014), and RBM15 (Moindrot et al., 2015). METTL16 methylates long non-coding RNA and U6 small nuclear RNA and regulates S-adenosylmethionine homeostasis (Pendleton et al., 2017; Warda et al., 2017). KIAA1429 and RBM15 are also components of methyltransferase complexes. KIAA1429 is required for full methylation in mammals (Schwartz et al., 2014). RBM15 mediates the formation of m6A in $\mathrm{X}$-inactive specific transcripts and cellular mRNAs (Moindrot et al., 2015). However, the detailed functions of these components are still poorly understood, and there are likely other mechanisms that remain to be investigated.

Reversible modifications of m6A can be removed by "erasers," such as fat mass and obesity-related protein (FTO) and ALKB homolog 5 protein (ALKBH5) (Jia et al., 2011; Zheng et al., 2013). These are ferrous iron- and $\alpha$-ketoglutarate-dependent demethylases, which can oxidatively remove m6A methylated groups from mRNA (Chen and Wong, 2020). Both FTO and ALKBH5 belong to the ALKB family of dioxygenases (Fedeles et al., 2015). FTO sequentially oxidizes m6A to N6hydroxymethyladeosine and N6-formyladenosine, which can be further hydrolyzed to adenine (Wei et al., 2018). ALKBH5 directly catalyzes the removal of m6A modifications. Recently, another m6A demethylase, ALKBH3, that preferentially act on m6A in tRNA rather than mRNA or rRNA has been reported (Ueda et al., 2017). Given that m6A is a dynamic modification in response to stimuli, demethylases ensure the equilibrium of $\mathrm{m} 6 \mathrm{~A}$ modifications in the transcriptome.

The last type of m6A regulatory proteins are "readers," which can recognize and bind to the m6A modification site in RNA and play an important role in different biological functions (Figure 2). The first m6A "reader" proteins identified were YTHDF1, YTHDF2, YTHDF3, YTHDC1, and YTHDC2, which contain a conserved YTH domain (YT521-B homology) (Liao et al., 2018). The YTH domain functions as a module that recognizes modifications and directly binds to m6A-modified RNA in the RRm6ACH consensus sequence (Roundtree et al., 2017a). YTHDF2, the first "reader" identified, accelerates mRNA degradation by binding $\mathrm{m} 6 \mathrm{~A}$ at the $3^{\prime}$ UTR and localizing the targeted mRNA to processing bodies (Ries et al., 2019). In addition, YTHDF2 can induce mRNA degradation through the recruitment of the CCR4-NOT deadenylation machinery (Du et al., 2016). Moreover, YTHDF2 has been found to prevent m6A modification in the $5^{\prime}$ UTR of the FTO protein by binding to the $\mathrm{m} 6 \mathrm{~A}$ site in the nucleus, thus promoting RNA translation in a cap-independent manner (Zhou et al., 2015). YTHDF1 binds to m6A sites around the stop codon and enhances mRNA translation by recruiting the eIF3 translation initiation complex (Wang et al., 2015; Chen and Wong, 2020). YTHDF3 has a fine-tuning effect on the RNA accessibility of YTHDF1 and YTHDF2 (Hu B. B et al., 2019). YTHDF3 can interact with YTHDF1 to improve RNA translation efficiency and combine with YTHDF2 to promote RNA degradation (Li et al., 2017; Shi et al., 2017). Recent-studies have revealed a new model 


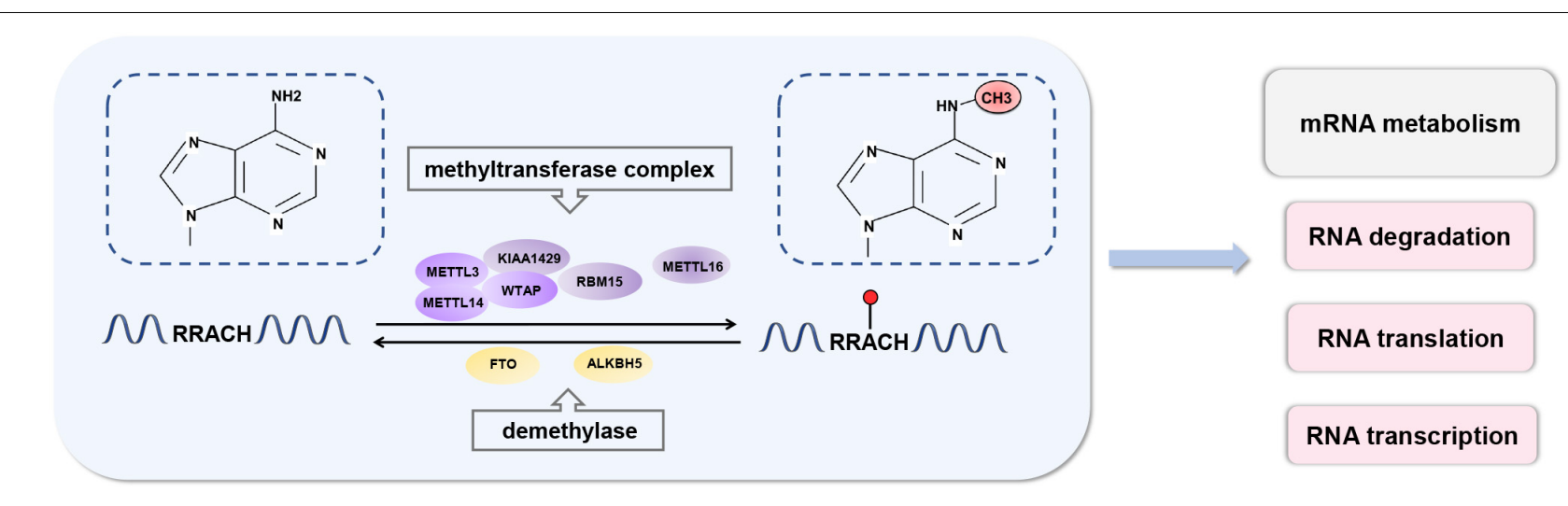

FIGURE 1 | Dynamic process of RNA N6-methyladenosine methylation. RNA m6A modification is a dynamic and reversible process. m6A can be installed by the methyltransferase complex and removed by demethylases. m6A modifications are enriched in the $3^{\prime}$-untranslated regions (UTRs) near the stop codons of mRNA and within internal long exons, mainly with a consensus sequence of RRACH. m6A participates in almost all processes in mRNA metabolism, including RNA transcription, translation, and degradation.

describing the functions of YTHDF proteins. YTHDF proteins function together to mediate mRNA degradation, and they show identical binding to all m6A sites in mRNA (Zaccara and Jaffrey, 2020). Each YTHDF paralog can compensate for the function of other YTHDF paralogs (Zaccara and Jaffrey, 2020). Another study confirmed the context-dependent functional compensation between YTHDF proteins (Lasman et al., 2020). YTHDC1 regulates RNA splicing and controls the nuclear export of its target RNA (Meyer and Jaffrey, 2017; Roundtree et al., 2017b). YTHDC2 promotes translation elongation by interacting with RNA helicases (Hsu et al., 2017). Three heterogeneous nuclear ribonucleoproteins (hnRNPs) are common "readers," namely hnRNPC, hnRNPG, and hnRNPA2B1 (Alarcón Claudio et al., 2015; Liu et al., 2015; Meyer Kate et al., 2015). These proteins indirectly bind to transcripts through the "m6A switch" mechanism. This mechanism relies on the ability of m6A to thermodynamically destabilize into short double helices. In this way, the single-stranded hnRNP binding motif is exposed and provides access to RNA-binding proteins. hnRNPC and hnRNPG influence mRNA localization and alternative splicing (König et al., 2010; Liu et al., 2015, 2017). HnRNPA2B1 promotes the transcription of precursor miRNA by binding to m6Acontaining primary miRNAs and interacting with the microRNA microprocessor complex (Alarcón Claudio et al., 2015). Recently, the IGFBP family IGFBP1-3 has been identified as a distinct family of m6A "readers" (Li et al., 2019; Müller et al., 2019; Wang S. et al., 2019). The binding motif of these proteins (UGGAC) overlaps with the consensus sequence of m6A. In addition, these proteins contain common RNA-binding domains that recognize m6A-containing transcripts. IGFBPs recruit RNA stabilizers that protect m6A-containing mRNA from degradation, thereby promoting the expression of target transcripts (He et al., 2019).

\section{Physiological Role of m6A RNA Modification}

Under normal conditions, m6A modification interferes with RNA recognition (Karikó et al., 2005). Viruses can use m6A modification to escape host immune recognition because of the presence of widely distributed $\mathrm{m} 6 \mathrm{~A}$ modifications in viral mRNA (Tang et al., 2021). In addition, mounting evidence has demonstrated m6A modifications in viral RNA (Durbin et al., 2016; Lu et al., 2020), host circRNAs (Chen et al., 2019), and normal endogenous ssRNA (Gao et al., 2020). m6A can serve as a key factor for the innate immune system to avoid abnormal immune recognition.

Innate immunity is activated immediately after the RNA recognition process, and it induces the production of cytokines, such as type I interferons (IFNs) (Winkler et al., 2019). $\mathrm{m} 6 \mathrm{~A}$ modification regulates the innate immune response by targeting IFN. IFNB1 mRNA can be modified by m6A within both the coding sequence and the $3^{\prime}$ UTR (Rubio et al., 2018). IFN production triggered by dsDNA or human cytomegalovirus (HCMV) is mediated by $\mathrm{m} 6 \mathrm{~A}$ regulators. METTL14 depletion reduces virus reproduction and promotes IFNB1 mRNA accumulation, thus affecting pathways related to metabolic reprogramming, stress responses, and aging (Rubio et al., 2018). ALKBH5 depletion decreases IFNB1 mRNA production by regulating antiviral immune responses (Rubio et al., 2018). Moreover, it has been reported that IFNB mRNA is stabilized by repression of METTL3 or YTHDF2 after viral infection or inactivated virus stimulation (Winkler et al., 2019). Together, these findings reveal the important role of m6A as a negative regulator of IFN response, consequently facilitating viral propagation.

\section{Role of RNA m6A in Inflammation: From Cells to Disease Progression}

$\mathrm{m} 6 \mathrm{~A}$ modifications can cause changes in inflammation-related genes during inflammation. A systematic study of m6A modified cross-linking, substrate genes, and modified regulation illustrated the mechanism of action of $\mathrm{m} 6 \mathrm{~A}$ in inflammation (Figure 3 and Table 1). In the following sections, we will elucidate the interaction between $\mathrm{m} 6 \mathrm{~A}$ modification and inflammation in the 


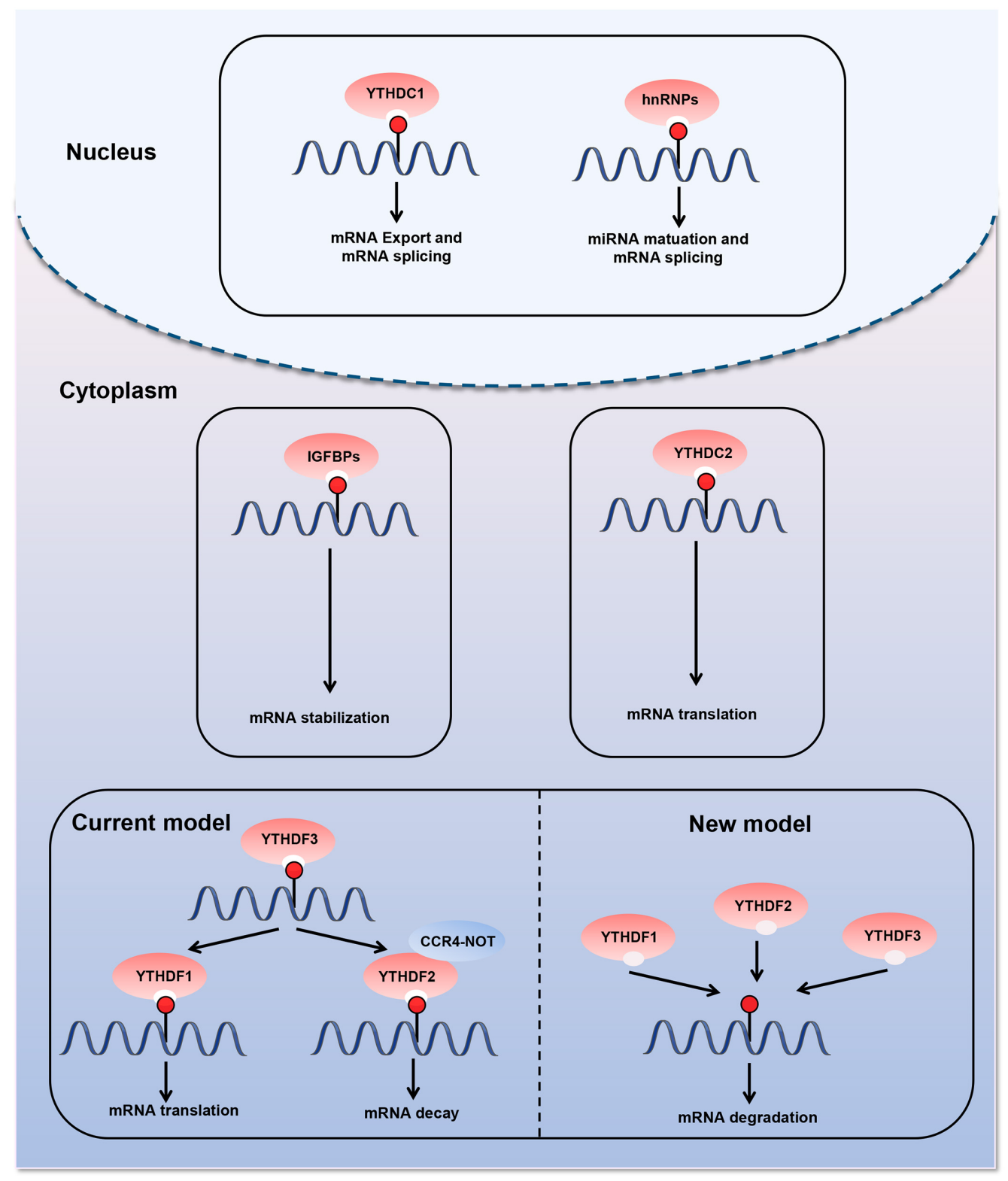

FIGURE 2 | Diverse biological consequences of m6A methylation by different m6A "readers." m6A "readers" can recognize and bind to the m6A modification sites in RNA. They play an important role in different biological functions. The first m6A "readers" identified were YTHDF1, YTHDF2, YTHDF3, YTHDC1, and YTHDC2, which contain a conserved YTH domain (YT521-B homology). Moreover, three heterogeneous nuclear ribonucleoproteins (hnRNPs) are common "readers," namely hnRNPC, hnRNPG, and hnRNPA2B1. m6A "readers" are involved in various steps of RNA metabolism, including pre-mRNA splicing, mRNA translation, nuclear export, and mRNA degradation.

pathogenesis of various diseases, including metabolic disorders, autoimmune diseases, and malignant diseases.

\section{Metabolic Disorders}

Under normal circumstances, the metabolic state of the human body is maintained under homeostasis. When normal metabolic processes are disrupted, metabolic disorders occur. $\mathrm{m} 6 \mathrm{~A}$ is involved in the regulation of gene expression and cellular metabolism. Accumulated data demonstrate the significant role of m6A methylation in metabolic homeostasis.
Lipopolysaccharide (LPS) is considered an early trigger of inflammation and metabolic diseases. The Fto gene, which encodes m6A demethylase, has been found to be responsive to LPS and play a role in linking inflammation with metabolic responses (Zhang et al., 2016). LPS stimulation reduced the expression of carnitine palmitoyltransferase 1 (CPT1) in the liver, upregulated the truncated cFTO4 protein, and dramatically reduced $\mathrm{m} 6 \mathrm{~A}$ levels near the translation start site of CPT1 (Zhang et al., 2016). In addition, the core methyltransferase of m6A, METTL3, has been found to participate in the molecular 


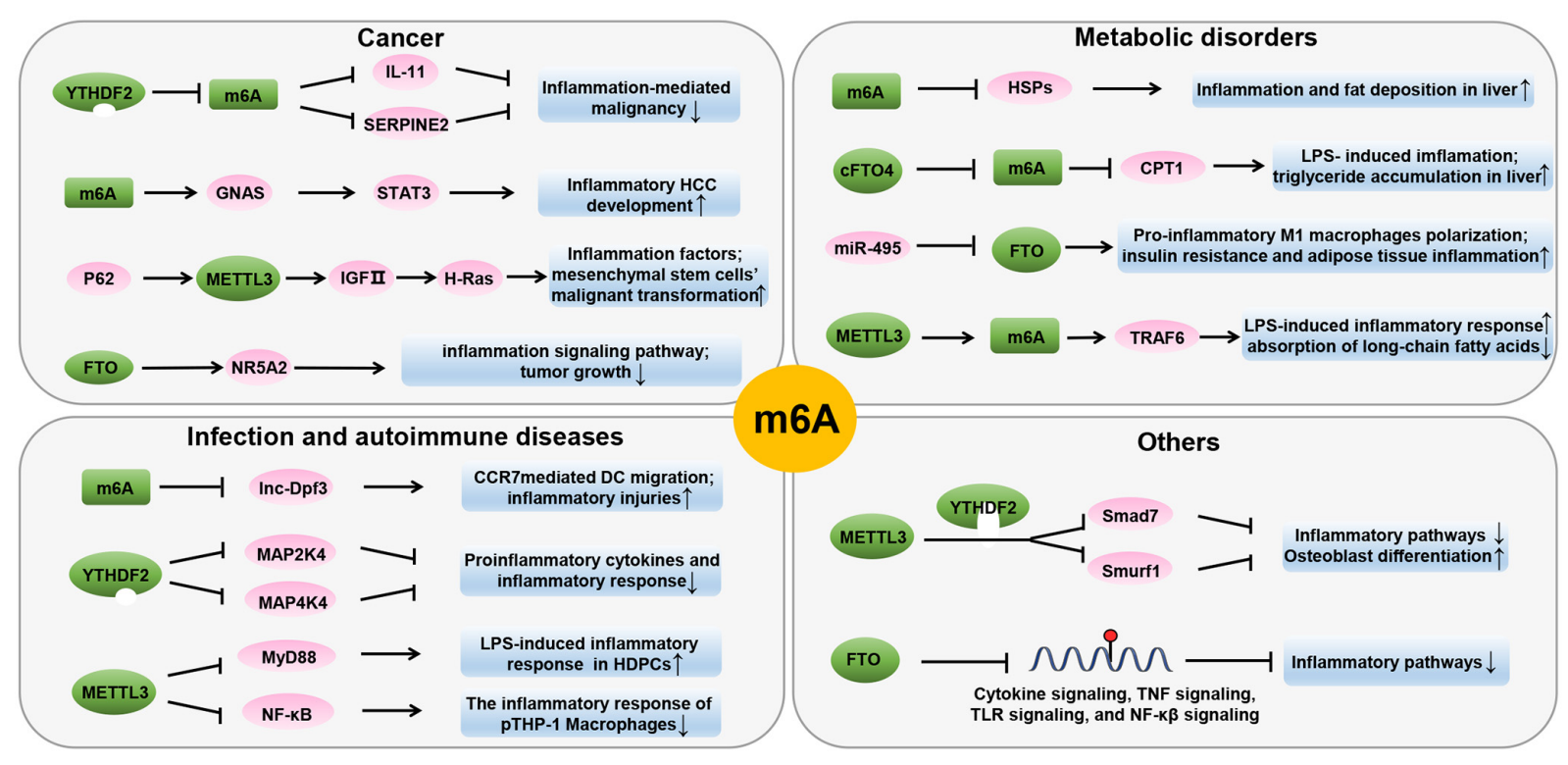

FIGURE 3 | Role of m6A in inflammatory processes of various diseases states. m6A modification affects inflammation by regulating inflammation-related genes. RNA methylation is linked through numerous mechanisms and present in various inflammatory disease states, including autoimmunity, infection, metabolic diseases, and cancer.

mechanism of inflammation-induced malabsorption of longchain fatty acids (LCFAs). METTL3 inhibits LPS-induced inflammatory response by exerting anti-malabsorption of LCFA activity in vitro (Zong et al., 2019). The depletion of Mettl3 reduces the m6A level of Traf6 mRNA, thereby decreasing the expression of TRAF6 and inhibiting the NF- $\kappa$ B and MAPK signaling pathways (Zong et al., 2019). These data suggest that m6A methylation plays an essential role in cellular metabolic homeostasis.

In obesity, extensive inflammation and stress reactions usually occur, which subsequently develop into chronic, low-grade, local inflammation and disruption of metabolic homeostasis (Ghemrawi et al., 2018). Studies have shown a correlation between inflammation and obesity. Experiments in obese mice have shown that the amounts of proinflammatory cytokines secreted by adipocytes and macrophages in adipose tissues are sufficient to disrupt insulin signaling (Olefsky and Glass, 2010). In addition, activation of the JNK and NF- $\kappa B$ signaling pathways causes obesity-induced inflammation and abnormal insulin action. The Fto gene is known to play an important role in the regulation of metabolic homeostasis, mainly owing to its association with body mass index (BMI). FTO overexpression increases food intake and promotes obesity (Church et al., 2010). miR-495 inhibited the expression of its target gene Fto, resulting in the promotion of the transformation of macrophages into M1-type pro-inflammatory macrophages, and aggravated insulin resistance and adipose tissue inflammation in type 2 diabetes mellitus (T2D) -mice (Hu et al., 2019a). In contrast, dominant point mutations in mouse Fto gene decreased fat mass, promoted energy expenditure, and improved the inflammatory profile of white adipose tissue of mutant mice (Church et al., 2009). Recent scientific literature has shed light on the genetic relationship between FTO and inflammation markers. Notably, studies have found that FTO is related to C-reactive protein (CRP) levels (Ligthart et al., 2016). Greater adiposity conferred by FTO SNPs leads to higher CRP levels (Welsh et al., 2010). Another study demonstrated that there was a significant positive correlation between hs-CRP, leptin, and broad BMI, but there was no significant difference in the FTO rs9939609 genotype (Zimmermann et al., 2011). Obesity is associated with a shorter telomere length (Zhou et al., 2017). Telomere length attrition may be affected by obesity-related inflammation, oxidative stress, and FTO gene pathways. The increase in BMI is genetically related to telomere length shortening, and low-grade inflammation may result from increased CRP levels (Rode et al., 2014). The association between the Fto gene and expression of inflammatory markers is unclear, and the underlying mechanisms remain to be elucidated.

Non-alcoholic fatty liver disease is accompanied by inflammation, which contributes to the development of fibrosis, cirrhosis, and hepatocellular carcinoma (HCC) (Sun et al., 2013). Chronic corticosterone exposure can induce liver inflammation and fibrosis and increase mRNA and m6A methylation of several heat shock proteins (HSPs) (Feng et al., 2020). HSPs are activated during acute stress response to exert a cytoprotective effect (Stolte et al., 2009), which has been confirmed to be related to $\mathrm{m} 6 \mathrm{~A}$-mediated post-transcriptional regulation. In addition, the present study demonstrated that FTO expression was significantly increased in the livers of non-alcoholic steatohepatitis (NASH) patients and in a rodent model of NASH (Lim et al., 2016). Genetic silencing of Fto had a protective effect on palmitate-induced oxidative stress, endoplasmic reticulum (ER) stress, and apoptosis in vitro (Lim et al., 2016). Inflammation is a characteristic of Metabolic syndrome (MetS). 
TABLE 1 | Roles of m6A in RNA metabolism and inflammatory processes.

\begin{tabular}{|c|c|c|c|c|c|c|c|c|}
\hline Disease & & $\begin{array}{l}\text { Aberrant } \\
\text { expression } \\
\text { of } \mathrm{m} 6 \mathrm{~A} \\
\text { enzymes }\end{array}$ & $\begin{array}{l}\text { Target } \\
\text { RNA }\end{array}$ & $\begin{array}{l}\text { Change } \\
\text { of target } \\
\text { RNA } \\
\text { level }\end{array}$ & $\begin{array}{l}\text { Effect of } \\
\text { enzyme on } \\
\text { target RNA }\end{array}$ & $\begin{array}{l}\text { Role of m6A in } \\
\text { diseases }\end{array}$ & Mechanism & References \\
\hline \multirow[t]{2}{*}{$\begin{array}{l}\text { Metabolic } \\
\text { disorders }\end{array}$} & Obesity & FTO $\uparrow$ & - & & & $\begin{array}{l}\text { Increase fat } \\
\text { mass, decrease } \\
\text { energy } \\
\text { expenditure }\end{array}$ & $\begin{array}{l}\text { Promotes inflammatory profile } \\
\text { in white adipose tissue; leads to } \\
\text { higher CRP levels }\end{array}$ & $\begin{array}{l}\text { Church et al., } \\
\text { 2009; } \\
\text { Zimmermann } \\
\text { et al., 2011; } \\
\text { Ligthart et al., } \\
2016\end{array}$ \\
\hline & $\mathrm{NASH}$ & FTO $\uparrow$ & - & & & $\begin{array}{l}\text { Promotes fat } \\
\text { accumulation, } \\
\text { inflammation, and } \\
\text { lipotoxicity in liver }\end{array}$ & $\begin{array}{l}\text { Genetic silencing of FTO } \\
\text { protects against } \\
\text { palmitate-induced oxidative } \\
\text { stress, mitochondrial } \\
\text { dysfunction, ER stress, and } \\
\text { apoptosis }\end{array}$ & Lim et al., 2016 \\
\hline \multirow[t]{2}{*}{$\begin{array}{l}\text { Autoimmune } \\
\text { diseases And } \\
\text { Infection }\end{array}$} & $\mathrm{RA}$ & METTL3 $\uparrow$ & (p)-NF-kB & $\downarrow$ & $\begin{array}{l}\text { Phosphorylation } \\
\text { and nucleus } \\
\text { translocation }\end{array}$ & $\begin{array}{l}\text { Increases } \\
\text { inflammatory } \\
\text { response in } \\
\text { macrophages }\end{array}$ & $\begin{array}{l}\text { Overexpression of METTL3 } \\
\text { significantly attenuated the } \\
\text { inflammatory response through } \\
\text { the effect on NF-кB }\end{array}$ & $\begin{array}{l}\text { Wang J. et al., } \\
2019\end{array}$ \\
\hline & $\begin{array}{l}\text { Dental pulp } \\
\text { inflammation }\end{array}$ & METTL3 $\uparrow$ & MyD88 & $\downarrow$ & Splicing & $\begin{array}{l}\text { Increases the } \\
\text { expression of } \\
\text { inflammatory } \\
\text { cytokines }\end{array}$ & $\begin{array}{l}\text { METTL3 regulate alternative } \\
\text { splicing of MyD88; METTL3 } \\
\text { depletion decreased the } \\
\text { expression of inflammatory } \\
\text { cytokines and the NF-kB } \\
\text { signaling and MAPK signaling } \\
\text { pathway }\end{array}$ & $\begin{array}{l}\text { Feng et al., } \\
2018\end{array}$ \\
\hline \multirow[t]{3}{*}{ Cancer } & $\mathrm{HCC}$ & YTHDF2 $\downarrow$ & $\begin{array}{l}\text { IL-11, } \\
\text { SERPINE2 }\end{array}$ & $\uparrow$ & Degradation & $\begin{array}{l}\text { Promotes } \\
\text { inflammation- } \\
\text { mediated } \\
\text { malignancy }\end{array}$ & $\begin{array}{l}\text { YTHDF2 processed the decay } \\
\text { of m6 A-containing IL11 and } \\
\text { SERPINE2 mRNAs; YTHDF2 } \\
\text { transcription succumbed to } \\
\text { HIF-2 } \alpha\end{array}$ & $\begin{array}{l}\text { Hou et al., } \\
2019\end{array}$ \\
\hline & $\mathrm{HCC}$ & Unknown & GNAS & $\uparrow$ & Expression & $\begin{array}{l}\text { Promotes } \\
\text { LPS-induced } \\
\text { HCC cell growth } \\
\text { and invasion }\end{array}$ & $\begin{array}{l}\text { Increasing m6A methylation of } \\
\text { GNAS mRNA, GNAS promotes } \\
\text { LPS-induced STAT3 activation } \\
\text { in HCC cells through inhibiting } \\
\text { long non-coding RNA TPTEP1 } \\
\text { interacting with STAT3 }\end{array}$ & $\begin{array}{l}\text { Ding et al., } \\
2020\end{array}$ \\
\hline & ICC & FTO $\downarrow$ & NR5A2 & $\downarrow$ & Expression & $\begin{array}{l}\text { Regulates } \\
\text { inflammatory } \\
\text { gene expression } \\
\text { and tumor growth }\end{array}$ & $\begin{array}{l}\text { FTO knockdown inhibited the } \\
\text { expression of NR5A2 which is } \\
\text { associated with PDAC and } \\
\text { transcriptionally regulates } \\
\text { inflammatory gene expression }\end{array}$ & $\begin{array}{l}\text { Rong et al., } \\
2019\end{array}$ \\
\hline Others & Poststroke & $\mathrm{FTO} \downarrow$ & - & & & $\begin{array}{l}\text { Modulates } \\
\text { poststroke brain } \\
\text { damage }\end{array}$ & $\begin{array}{l}\text { Promotes cytokine signaling, } \\
\text { TNF signaling, TLR signaling, } \\
\text { and NF-kB signaling pathways }\end{array}$ & $\begin{array}{l}\text { Chokkalla et al., } \\
2019\end{array}$ \\
\hline
\end{tabular}

FTO may serve as a risk factor for MetS and inflammatory markers (Kraja et al., 2014). Thus, m6A methylation regulators can act as a link between inflammation and metabolic responses. These findings also warrant further investigation.

\section{Autoimmune Diseases and Infections}

Inflammation is primarily caused by immune cells and cytokines. Inflammatory cells are composed of various immune cells, including neutrophils, macrophages, lymphocytes, and plasma cells. Cytokines are composed of inflammatory mediators, such as interleukin-1 $\beta$ (IL-1 $\beta$ ), IL-6, and tumor necrosis factor- $\alpha$ (TNF$\alpha)$ (Medzhitov, 2008). The presence of m6A modifications has been reported in both autoimmune diseases and infections.
Peripheral dendritic cells (DCs) mature in response to microbial products or inflammatory signals and then upregulate CC-chemokine receptor 7 (CCR7). m6A modification plays a critical role in DC-dependent inflammatory response. CCR7 stimulation upregulates $\operatorname{lnc}$-Dpf3 by removing m6A modification to prevent RNA degradation (Liu et al., 2019). Lnc-Dpf3 feedback restrains CCR7-induced DC migration and inflammatory response. Macrophages play an important role in various chronic diseases. Recent studies have shown that m6A modification is involved in regulating macrophage phenotype. Silencing the m6A "reader" YTHDF2 increases MAP2K4 and MAP4K4 mRNA expression levels by stabilizing mRNA transcription, which in turn activates MAPK and NF- $\mathrm{B}$ signaling pathways, further 
inducing the expression of pro-inflammatory cytokines and aggravating inflammatory response in LPS-stimulated RAW 264.7 cells (Yu et al., 2019). Rheumatoid arthritis (RA) is a chronic inflammatory autoimmune disease characterized by the progressive destruction of the articular cartilage and bone (Scott et al., 2010). Studies have shown that m6A modification is involved in RA pathogenesis. It has been reported that METTL3 expression significantly increased in RA patients and is positively correlated with CRP and ESR, the two common markers of RA disease activity (Wang J. et al., 2019). In addition, an in vitro study showed that LPS stimulation promoted the expression and biological activity of METTL3 in macrophages. However, overexpression of METTL3 can attenuate LPS-induced inflammation through the NF- $\mathrm{BB}$ signaling pathway (Wang J. et al., 2019).

Commensal bacteria, especially gut microbiota, play a role in critical physiological functions such as host metabolism, immune system development, and even behavior (Sommer and Backhed, 2016). Metabolites and fermentation products from gut microbiota have been reported to mediate intestinal effects in the host by regulating transcription and epigenetic modifications (Koh et al., 2016; Agus et al., 2018). Variations in the gut microbiota correlate with $\mathrm{m} 6 \mathrm{~A}$ modifications in the cecum. METTL16 is another N6-adenosine-methyltransferase (Pendleton et al., 2017; Shima et al., 2017; Warda et al., 2017). A previous study reported that METTL16 expression decreases in the absence of microbiota. The target mRNA, Mat2a, which encodes S-adenosylmethionine synthase, is less methylated (Jabs et al., 2020). FTO deletion in mice resulted in changes in bacterial characteristics associated with reduced inflammation, such as a higher abundance of Lactobacillus and a lower content of Porphyromonadaceae and Helicobacter (Sun et al., 2019). Helicobacter pylori interacts with gastric epithelial cells to induce gastric inflammation and epithelial damage. The expression of WTAP has been confirmed to be downregulated in AGS cells stimulated by $H$. pylori (Kim et al., 2007). Dental pulp inflammation is a common public health problem caused by oral bacterial infections. It has been reported that $\mathrm{m} 6 \mathrm{~A}$ levels and METTL3 expression are increased in LPS-stimulated human dental pulp cells (HDPCs). METTL3 deletion promotes the expression of MyD88S in HDPCs induced by LPS, reduces the expression of inflammatory cytokines, and inhibits the activation of the NF-кB and MAPK signaling pathways (Feng et al., 2018). These studies suggest that epitranscriptomic modifications act as an additional level of interaction between commensal bacteria and their host, affecting pathways related to inflammation and antimicrobial responses.

\section{Cancer}

Inflammation is associated with the development of a cancerprone microenvironment. Many types of tumors occur in these inflammatory microenvironments, and the inflammatory state can be pro-tumorigenic (Singh et al., 2017). Studies have shown that a disruption in the balance between pro-and antiinflammatory mechanisms leads to chronic inflammation, which can induce tumor initiation and progression (Seruga et al., 2008). As inflammation progresses, it promotes the production of tumor-promoting cytokines (Singh et al., 2017) such as IL11 (Bollrath et al., 2009), IL-1 $\beta$ (Tu et al., 2008), and IL-6 (Grivennikov et al., 2009; Singh et al., 2017), which support the survival, growth, and metastasis of tumor cells (Garg et al., 2012). Recently, numerous studies have suggested an association between $\mathrm{m} 6 \mathrm{~A}$ modifications and pro-inflammatory genes in the tumor microenvironment.

In the complex tumor microenvironment network, mesenchymal stromal cells (MSCs) play a key role in promoting tumor progression by interacting with tumor cells and other stromal cells (Pelizzo et al., 2018; Whiteside, 2018). The inflammation and autophagy-related gene P62 is highly expressed in most human tumor tissues (Moscat and Diaz-Meco, 2009; Ren et al., 2014). It has been demonstrated that P62 synergizes with TNF- $\alpha$ to promote the malignant transformation of human MSCs by forming insulin growth factor II (IGF-II) promoter-enhancer chromatin loops and increasing METTL3 occupancy on IGFII $3^{\prime}$ UTR, and upregulates the expression of H-Ras by harboring inflammation-related factors, such as TNFR1, CLYD, EGR1, NF- $\kappa B$, TLR4, and PPAR $\gamma$ (Xin et al., 2018). In HCC, m6A modification levels and mRNA expression are increased. A recent study found that the deletion of the m6A "reader" YTHDF2 in human HCC cells or mouse hepatocytes aggravates inflammation, vascular reconstruction, and metastatic progression (Hou et al., 2019). YTHDF2 promotes the decay of m6A-containing IL-11 and serpin family E member 2 (SERPINE2) mRNAs, which are involved in inflammationmediated malignant tumors and the destruction of normal blood vessels (Hou et al., 2019). Another study reported that LPS stimulation can increase m6A methylation of G-protein alpha-subunit (GNAS) mRNA to promote GNAS expression in HCC cells. Highly expressed GNAS promotes the growth and invasion of HCC cells by interacting with STAT3 (Ding et al., 2020). Intrahepatic cholangiocarcinoma (ICC) is the second most malignant type of primary liver cancer with a high degree of incidence and a very poor prognosis. FTO was found to regulate the inflammatory signaling pathways in clinical ICC samples. FTO knockdown inhibited the expression of NR5A2, which is a nuclear receptor related to pancreatic adenocarcinoma and transcriptionally regulates the expression of inflammatory genes (Rong et al., 2019). Moreover, the expression level of FTO was decreased in clinical ICC samples and inversely correlated with CA19-9 expression and micro-vessel density (MVD) (Rong et al., 2019). Thus, these results suggest that FTO may be a target for predicting the prognosis of ICC. It has recently been found that the evaluation of $\mathrm{m} 6 \mathrm{~A}$ modification patterns within individual tumors could predict tumor inflammation stage and prognosis in gastric cancer (Zhang et al., 2020). A low m6A score, characterized by increased mutation burden and activation of immunity, has a higher 5-year survival rate. However, activation of the stroma and lack of effective immune infiltration were observed in the high m6A score subtype and associated with poorer survival. Patients with a lower m6A score demonstrated significant therapeutic and clinical benefits. In addition, m6A modification of non-coding RNAs can affect tumor formation. METTL3 may have an oncogenic role in bladder cancer by positively modulating 


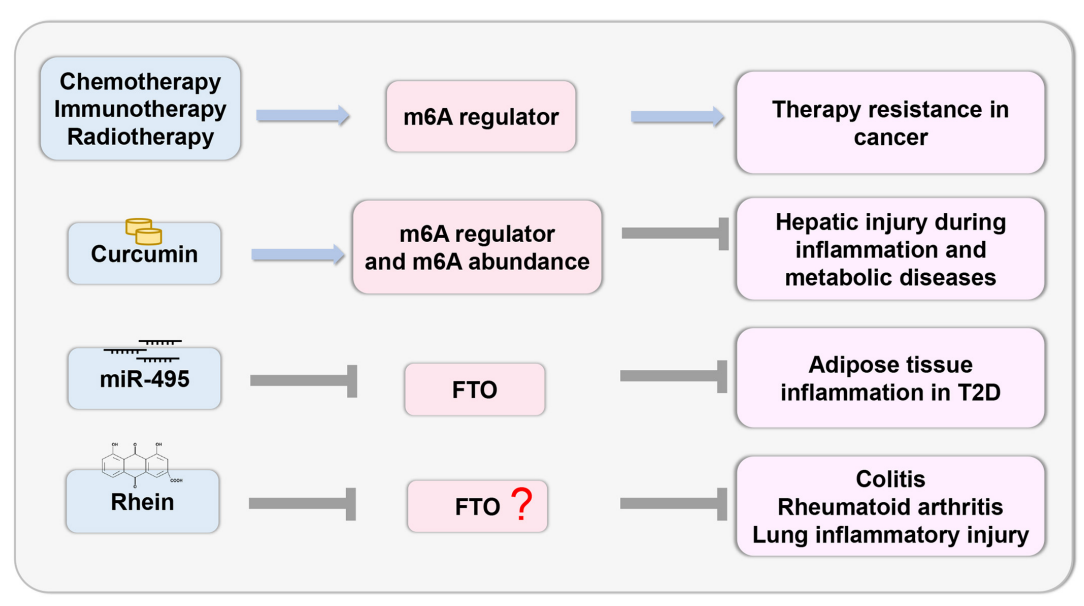

FIGURE 4 | Therapeutic potential based on m6A. The study of epigenetic changes in inflammatory response provides the possibility to develop effective drugs with specific targets based on the $\mathrm{m} 6 \mathrm{~A}$ regulator.

pri-miR221/222 maturation in an m6A-dependent manner (Han et al., 2019).

\section{Others}

Many infectious diseases, such as osteomyelitis, osteoarthritis, and periodontitis, can disrupt bone homeostasis (Josse et al., 2015; Pacios et al., 2015; Maruotti et al., 2017). LPS is the main pathogenic factor in infectious bone destruction. Studies have revealed that METTL3 knockdown stabilizes Smad7 and Smurf1 mRNA transcripts via YTHDF2 to inhibit osteoblast differentiation and Smad-dependent signaling, and regulates MAPK signaling to activate inflammatory response to LPS (Zhang et al., 2019). A previous study emphasized the influence of genetic risk for obesity and osteoarthritis, but the association is only regulated by the effect on BMI, which is consistent with what is known about the biology of the FTO gene (Panoutsopoulou et al., 2014).

Neuronal fate after ischemic stroke is determined by intricate biochemical and molecular events, including oxidative stress, ER stress, apoptosis, and inflammation (Mehta et al., 2007). The brain has been shown to have higher m6A abundance than other mammalian organs (Meyer et al., 2012). Thus, post-transcriptional regulators fine-tune the post-ischemic pathophysiology. An in silico analysis demonstrated increased m6A methylation in major inflammatory pathways, including IL-6 cytokine, TNF, TLR, and NF- $\kappa \mathrm{B}$ signaling pathways. The expression of major neuronally localized m6A demethylase FTO was downregulated, which presumably leads to decreased demethylation of m6A tagged RNAs in the post-stroke brain. However, ALKBH5 expression was unaltered in the ischemic brain (Chokkalla et al., 2019). In addition, a decrease in total m6A demethylase activity was reported in the study, indicating that FTO downregulation might be responsible for the decreased m6A demethylation in the post-stroke brain (Chokkalla et al., 2019). Therefore, it is plausible that ischemia-induced loss of FTO might be a modulator of post-ischemic secondary brain damage.
As a major cause of mortality worldwide, cardiovascular and metabolic diseases have a higher risk of occurrence in people with high levels of systemic inflammation and are independent of traditional cardiometabolic risk factors (Danesh et al., 2004). A recent study evaluated the association between inflammation and cardiometabolic phenotypes. The genetic overlap includes FTO, which has been confirmed to have an effect on CRP (Ligthart et al., 2015). Owing to its role in obesitypredisposing genetic variants, FTO has been shown to have nominally significant associations with cardiovascular disease and is referred to as a cardiovascular biomarker (He et al., 2010).

Polycystic ovary syndrome (PCOS) is a highly heterogeneous disease of the reproductive system that is associated with cellular metabolism and chronic inflammation (Ojeda-Ojeda et al., 2013). It has been reported that SNP rs9939609 of FTO is significantly related to PCOS (Zhao et al., 2016). Notably, FTO is a risk factor for PCOS that is independent of its correlation with BMI or obesity (Zhao et al., 2016). Therefore, the FTO gene has a profound effect on PCOS and is considered a candidate gene for this disorder.

\section{Therapeutic Potential}

Recent studies have demonstrated that deregulation of $\mathrm{m} 6 \mathrm{~A}$ regulators is linked to cancer therapy resistance. Chemotherapeutic drugs modulate $\mathrm{m} 6 \mathrm{~A}$ regulators to stabilize the mRNA of oncogenes and induce chemoresistance (Shriwas et al., 2020). The tumor microenvironment activated by m6A regulators induces resistance to immunotherapy in cancer cells (Yang et al., 2019; Yi et al., 2020). Radiation stabilizes the mRNA of cancer stem cells by modulating the m6A regulator (Taketo et al., 2018; Visvanathan et al., 2018). As m6A plays an important role in therapy resistance, the targeted inhibition of m6A regulators may lead to better outcomes.

The study of epigenetic changes in inflammatory response provides the possibility of developing effective drugs with specific targets (Figure 4). Recently, curcumin, a yellow polyphenolic pigment derived from the spice turmeric (Curcuma longa), has 
been reported to protect against LPS-induced liver injury and lipid metabolism disorders. Dietary curcumin can regulate the mRNA expression of METTL3, METTL14, ALKBH5, FTO, and YTHDF2 and increase m6A abundance, which has a protective effect on hepatic injury due to inflammation and metabolic diseases (Lu et al., 2018). In T2D, miR-495 inhibited FTO expression, thus promoting the transformation of macrophages into M1-type pro-inflammatory macrophages, and aggravated insulin resistance and adipose tissue inflammation (Hu et al., 2019a). Thus, this research provides a theoretical basis for targeted treatment. Notably, there are few inhibitors that specifically target $\mathrm{m} 6 \mathrm{~A}$ regulatory proteins. The natural product Rhein, which is identified as a demethylase FTO inhibitor, competitively binds to the FTO active site in vitro (Chen et al., 2012). Rhein has been found to suppress ATPtriggered inflammatory responses in fibroblast-like synoviocytes of rheumatoid rats and ameliorate experimental colitis ( $\mathrm{Hu}$ et al., 2019b; Wu et al., 2020). In addition, Rhein treatment can inhibit inflammatory lung injury induced by the human respiratory syncytial virus (Shen et al., 2019). However, whether these protective effects are mediated by m6A modifications remain to be investigated. Thus, more efficacious medicines and novel therapeutic strategies related to m6A modification should be explored.

\section{PERSPECTIVES AND CONCLUSION}

Although m6A has become the focus of numerous studies, the mechanism by which m6A modifications affect inflammation in human diseases remains unclear. For instance, human HCC exhibits a characteristic increase in $\mathrm{m} 6 \mathrm{~A}$ modification, which is related to inflammation-mediated malignancy (Hou et al., 2019). Meanwhile, LPS stimulation can increase m6A levels and trigger inflammatory cytokine production and pathways in liver tumors and dental pup inflammation (Feng et al., 2018; Ding et al., 2020). Mechanistically, it has been reported that silencing Mettl3 could maintain LCFA absorption by blocking

\section{REFERENCES}

Agus, A., Planchais, J., and Sokol, H. (2018). Gut Microbiota Regulation of Tryptophan Metabolism in Health and Disease. Cell Host Microbe 23, 716-724. doi: 10.1016/j.chom.2018.05.003

Alarcón Claudio, R., Goodarzi, H., Lee, H., Liu, X., Tavazoie, S., and Tavazoie Sohail, F. (2015). HNRNPA2B1 Is a Mediator of m6A-Dependent Nuclear RNA Processing Events. Cell 162, 1299-1308. doi: 10.1016/j.cell.2015.08.011

Barbieri, I., Tzelepis, K., Pandolfini, L., Shi, J., Millán-Zambrano, G., Robson, S. C., et al. (2017). Promoter-bound METTL3 maintains myeloid leukaemia by m(6)A-dependent translation control. Nature 552, 126-131. doi: 10.1038/ nature 24678

Batista, P. J. (2017). The RNA Modification N(6)-methyladenosine and Its Implications in Human Disease. Genom. Proteom. Bioinform. 15, 154-163. doi: 10.1016/j.gpb.2017.03.002

Bayarsaihan, D. (2011). Epigenetic mechanisms in inflammation. J. Dent. Res. 90, 9-17. doi: 10.1177/0022034510378683

Bollrath, J., Phesse, T. J., von Burstin, V. A., Putoczki, T., Bennecke, M., Bateman, T., et al. (2009). gp130-Mediated Stat3 Activation in Enterocytes Regulates Cell the TRAF6-dependent inflammation response (Zong et al., 2019). However, METTL3 depletion enhances the expression of proinflammatory cytokines and promotes the activation of MAPK and NF- $\kappa$ B signaling pathways in osteoblasts (Zhang et al., 2019). In RA, LPS stimulation upregulates the expression and biological activity of METTL3 in macrophages, while METTL3 overexpression inhibited the inflammatory response (Wang J. et al., 2019). These data suggest that the associations between m6A modifications and inflammatory responses are highly dependent on the context of specific diseases and signaling molecules, especially as many m6A regulators are still being investigated to identify novel functions.

In summary, RNA methylation plays essential roles in various inflammatory disease states, including autoimmunity, infection, metabolic disease, cancer, neurodegenerative disease, heart disease, and bone disease via multiple mechanisms. Nevertheless, our understanding of this phenomenon is still incomplete. A major challenge is to study the precise functions of each m6A regulatory factor in different cells during the inflammatory response at various stages of disease development. In addition, other components of $\mathrm{m} 6 \mathrm{~A}$ modification remain to be discovered. Importantly, the development of scientific technology, such as the application of m6A mapping methods and m6A editing tools, will be immensely helpful for future research on m6A modification at the single nucleotide level.

\section{AUTHOR CONTRIBUTIONS}

TX and KS: concept and design. JL: drafting the manuscript. All authors: revising the manuscript content and approving the final version of the manuscript.

\section{FUNDING}

This study was supported by the National Natural Science Foundation of China (no. 82072556).

Survival and Cell-Cycle Progression during Colitis-Associated Tumorigenesis. Cancer Cell 15, 91-102. doi: 10.1016/j.ccr.2009.01.002

Chen, B., Ye, F., Yu, L., Jia, G., Huang, X., Zhang, X., et al. (2012). Development of cell-active N6-methyladenosine RNA demethylase FTO inhibitor. J. Am. Chem. Soc. 134, 17963-17971. doi: 10.1021/ja3064149

Chen, M., and Wong, C.-M. (2020). The emerging roles of N6-methyladenosine (m6A) deregulation in liver carcinogenesis. Mol. Cancer 19:44. doi: 10.1186/ s12943-020-01172-y

Chen, Y. G., Chen, R., Ahmad, S., Verma, R., Kasturi, S. P., Amaya, L., et al. (2019). N6-Methyladenosine Modification Controls Circular RNA Immunity. Mol. Cell 76, 96.e-109.e. doi: 10.1016/j.molcel.2019.07.016

Chokkalla, A. K., Mehta, S. L., Kim, T., Chelluboina, B., Kim, J., and Vemuganti, R. (2019). Transient Focal Ischemia Significantly Alters the m(6)A Epitranscriptomic Tagging of RNAs in the Brain. Stroke 50, 2912-2921. doi: 10.1161/strokeaha.119.026433

Church, C., Lee, S., Bagg, E. A., McTaggart, J. S., Deacon, R., Gerken, T., et al. (2009). A mouse model for the metabolic effects of the human fat mass and obesity associated FTO gene. PLoS Genet. 5:e1000599. doi: 10.1371/journal. pgen.1000599 
Church, C., Moir, L., McMurray, F., Girard, C., Banks, G. T., Teboul, L., et al. (2010). Overexpression of Fto leads to increased food intake and results in obesity. Nat. Genet. 42, 1086-1092. doi: 10.1038/ng.713

Dai, D., Wang, H., Zhu, L., Jin, H., and Wang, X. (2018). N6-methyladenosine links RNA metabolism to cancer progression. Cell Death Dis. 9:124. doi: 10. 1038/s41419-017-0129-x

Danesh, J., Wheeler, J. G., Hirschfield, G. M., Eda, S., Eiriksdottir, G., Rumley, A., et al. (2004). C-reactive protein and other circulating markers of inflammation in the prediction of coronary heart disease. N. Engl. J. Med. 350, 1387-1397. doi: 10.1056/NEJMoa032804

Desrosiers, R., Friderici, K., and Rottman, F. (1974). Identification of methylated nucleosides in messenger RNA from Novikoff hepatoma cells. Proc. Natl. Acad. Sci. U. S. A. 71, 3971-3975. doi: 10.1073/pnas.71.10.3971

Ding, H., Zhang, X., Su, Y., Jia, C., and Dai, C. (2020). GNAS promotes inflammation-related hepatocellular carcinoma progression by promoting STAT3 activation. Cell Mol. Biol. Lett. 25:8. doi: 10.1186/s11658-020-00204-1

Dominissini, D., Moshitch-Moshkovitz, S., Schwartz, S., Salmon-Divon, M., Ungar, L., Osenberg, S., et al. (2012). Topology of the human and mouse m6A RNA methylomes revealed by m6A-seq. Nature 485, 201-206. doi: 10.1038/ nature 11112

Du, H., Zhao, Y., He, J., Zhang, Y., Xi, H., Liu, M., et al. (2016). YTHDF2 destabilizes m6A-containing RNA through direct recruitment of the CCR4-NOT deadenylase complex. Nat. Commun. 7:12626. doi: 10.1038/ ncomms 12626

Dubin, D. T., and Taylor, R. H. (1975). The methylation state of poly A-containing messenger RNA from cultured hamster cells. Nucleic Acids Res. 2, 1653-1668. doi: $10.1093 /$ nar/2.10.1653

Dunning, T. (2009). Periodontal disease- the overlooked diabetes complication. Nephrol. Nurs. J. 36, 489-495.

Durbin, A. F., Wang, C., Marcotrigiano, J., and Gehrke, L. (2016). RNAs Containing Modified Nucleotides Fail To Trigger RIG-I Conformational Changes for Innate Immune Signaling. mBio 7:5. doi: 10.1128/mBio.00833-16

Fedeles, B. I., Singh, V., Delaney, J. C., Li, D., and Essigmann, J. M. (2015). The AlkB Family of Fe(II)/ $\alpha$-Ketoglutarate-dependent Dioxygenases: Repairing Nucleic Acid Alkylation Damage and Beyond. J. Biol. Chem. 290, 20734-20742. doi: $10.1074 /$ jbc.R115.656462

Feng, Y., Hu, Y., Hou, Z., Sun, Q., Jia, Y., and Zhao, R. (2020). Chronic corticosterone exposure induces liver inflammation and fibrosis in association with $\mathrm{m}(6) \mathrm{A}$-linked post-transcriptional suppression of heat shock proteins in chicken. Cell Stress Chaper. 25, 47-56. doi: 10.1007/s12192-019-01034-7

Feng, Z., Li, Q., Meng, R., Yi, B., and Xu, Q. (2018). METTL3 regulates alternative splicing of MyD88 upon the lipopolysaccharide-induced inflammatory response in human dental pulp cells. J. Cell. Mol. Med. 22, 2558-2568. doi: $10.1111 /$ jcmm. 13491

Fu, Y., Dominissini, D., Rechavi, G., and He, C. (2014). Gene expression regulation mediated through reversible m6A RNA methylation. Nat. Rev. Genet. 15, 293-306. doi: 10.1038/nrg3724

Gao, Y., Vasic, R., Song, Y., Teng, R., Liu, C., Gbyli, R., et al. (2020). m(6)A Modification Prevents Formation of Endogenous Double-Stranded RNAs and Deleterious Innate Immune Responses during Hematopoietic Development. Immunity 52, 1007-1021.e. doi: 10.1016/j.immuni.2020.05.003

Garg, A. D., Kaczmarek, A., Krysko, O., Vandenabeele, P., Krysko, D. V., and Agostinis, P. E. R. (2012). stress-induced inflammation: does it aid or impede disease progression? Trends Mol. Med. 18, 589-598. doi: 10.1016/j.molmed. 2012.06.010

Ghemrawi, R., Battaglia-Hsu, S.-F., and Arnold, C. (2018). Endoplasmic Reticulum Stress in Metabolic Disorders. Cells 7:63. doi: 10.3390/cells7060063

Grivennikov, S., Karin, E., Terzic, J., Mucida, D., Yu, G.-Y., Vallabhapurapu, S., et al. (2009). IL-6 and Stat3 are required for survival of intestinal epithelial cells and development of colitis-associated cancer. Cancer Cell. 15, 103-113. doi: 10.1016/j.ccr.2009.01.001

Han, J., Wang, J. Z., Yang, X., Yu, H., Zhou, R., Lu, H. C., et al. (2019). METTL3 promote tumor proliferation of bladder cancer by accelerating pri-miR221/222 maturation in m6A-dependent manner. Mol. Cancer 18:110. doi: 10.1186/ s12943-019-1036-9

Hawiger, J., and Zienkiewicz, J. (2019). Decoding inflammation, its causes, genomic responses, and emerging countermeasures. Scand. J. Immunol. 90:e12812. doi: $10.1111 /$ sji. 12812
He, L., Li, H., Wu, A., Peng, Y., Shu, G., and Yin, G. (2019). Functions of N6methyladenosine and its role in cancer. Mol. Cancer 18:176. doi: 10.1186/ s12943-019-1109-9

He, M., Cornelis, M. C., Franks, P. W., Zhang, C., Hu, F. B., and Qi, L. (2010). Obesity genotype score and cardiovascular risk in women with type 2 diabetes mellitus. Arteriosc. Thromb. Vasc. Biol. 30, 327-332. doi: 10.1161/ATVBAHA. 109.196196

Hou, J., Zhang, H., Liu, J., Zhao, Z., Wang, J., Lu, Z., et al. (2019). YTHDF2 reduction fuels inflammation and vascular abnormalization in hepatocellular carcinoma. Mol. Cancer 18:163. doi: 10.1186/s12943-019-1082-3

Hsu, P. J., Zhu, Y., Ma, H., Guo, Y., Shi, X., Liu, Y., et al. (2017). Ythdc2 is an N(6)methyladenosine binding protein that regulates mammalian spermatogenesis. Cell. Res. 27, 1115-1127. doi: 10.1038/cr.2017.99

Hu, B.-B., Wang, X.-Y., Gu, X.-Y., Zou, C., Gao, Z.-J., Zhang, H., et al. (2019). N(6)methyladenosine (m(6)A) RNA modification in gastrointestinal tract cancers: roles, mechanisms, and applications. Mol. Cancer 18:178. doi: 10.1186/s12943019-1099-7

Hu, F., Tong, J., Deng, B., Zheng, J., and Lu, C. (2019a). MiR-495 regulates macrophage M1/M2 polarization and insulin resistance in high-fat diet-fed mice via targeting FTO. Pflugers Archiv. 471, 1529-1537. doi: 10.1007/s00424019-02316-w

Hu, F., Zhu, D., Pei, W., Lee, I., Zhang, X., Pan, L., et al. (2019b). Rhein inhibits ATP-triggered inflammatory responses in rheumatoid rat fibroblastlike synoviocytes. Int. Immunopharmacol. 75:105780. doi: 10.1016/j.intimp. 2019.105780

Jabs, S., Biton, A., and Becavin, C. (2020). Impact of the gut microbiota on the m(6)A epitranscriptome of mouse cecum and liver. Nat. Commun. 11:1344. doi: 10.1038/s41467-020-15126-x

Jia, G., Fu, Y., Zhao, X., Dai, Q., Zheng, G., Yang, Y., et al. (2011). N6methyladenosine in nuclear RNA is a major substrate of the obesity-associated FTO. Nat. Chem. Biol. 7, 885-887. doi: 10.1038/nchembio.687

Josse, J., Velard, F., and Gangloff, S. C. (2015). Staphylococcus aureus vs. Osteoblast: Relationship and Consequences in Osteomyelitis. Front. Cell. Infect. Microbiol. 5:85. doi: 10.3389/fcimb.2015.00085

Jung, Y., and Goldman, D. (2018). Role of RNA modifications in brain and behavior. Genes Brain Behav. 17:e12444. doi: 10.1111/gbb.12444

Kane, S. E., and Beemon, K. (1985). Precise localization of m6A in Rous sarcoma virus RNA reveals clustering of methylation sites: implications for RNA processing. Mol. Cell. Biol. 5:2298. doi: 10.1128/MCB.5.9.2298

Karikó, K., Buckstein, M., Ni, H., and Weissman, D. (2005). Suppression of RNA recognition by Toll-like receptors: the impact of nucleoside modification and the evolutionary origin of RNA. Immunity 23, 165-175. doi: 10.1016/j.immuni. 2005.06.008

Kim, N., Park, W. Y., Kim, J. M., Park, Y. S., Lee, D. H., Park, J. H., et al. (2007). Analysis of Gene Expression Profile of AGS Cells Stimulated by Helicobacter pylori Adhesion. Gut. Liver 1, 40-48. doi: 10.5009/gnl.2007.1.1.40

Koh, A., De Vadder, F., Kovatcheva-Datchary, P., and Backhed, F. (2016). From Dietary Fiber to Host Physiology: Short-Chain Fatty Acids as Key Bacterial Metabolites. Cell 165, 1332-1345. doi: 10.1016/j.cell.2016.05.041

König, J., Zarnack, K., Rot, G., Curk, T., Kayikci, M., Zupan, B., et al. (2010). iCLIP reveals the function of hnRNP particles in splicing at individual nucleotide resolution. Nat. Struct. Mol. Biol. 17, 909-915. doi: 10.1038/nsmb.1838

Kraja, A. T., Chasman, D. I., North, K. E., Reiner, A. P., Yanek, L. R., Kilpeläinen, T. O., et al. (2014). Pleiotropic genes for metabolic syndrome and inflammation. Mol. Genet. Metab. 112, 317-338. doi: 10.1016/j.ymgme.2014.04.007

Lasman, L., Krupalnik, V., Viukov, S., Mor, N., Aguilera-Castrejon, A., Schneir, D., et al. (2020). Context-dependent functional compensation between Ythdf m(6)A reader proteins. Genes. Dev. 34, 1373-1391. doi: 10.1101/gad.340695. 120

Li, A., Chen, Y.-S., Ping, X.-L., Yang, X., Xiao, W., Yang, Y., et al. (2017). Cytoplasmic m6A reader YTHDF3 promotes mRNA translation. Cell. Res. 27, 444-447. doi: 10.1038/cr.2017.10

Li, T., Hu, P.-S., Zuo, Z., Lin, J.-F., Li, X., Wu, Q.-N., et al. (2019). METTL3 facilitates tumor progression via an m(6)A-IGF2BP2-dependent mechanism in colorectal carcinoma. Mol. Cancer 18:112. doi: 10.1186/s12943-019-1038-7

Li, X., Xiong, X., Wang, K., Wang, L., Shu, X., Ma, S., et al. (2016). Transcriptomewide mapping reveals reversible and dynamic $\mathrm{N}(1)$-methyladenosine methylome. Nat. Chem. Biol. 12, 311-316. doi: 10.1038/nchembio.2040 
Liao, S., Sun, H., and Xu, C. Y. T. H. (2018). Domain: A Family of N(6)methyladenosine (m(6)A) Readers. Genom. Proteom. Bioinform. 16, 99-107. doi: 10.1016/j.gpb.2018.04.002

Ligthart, S., de Vries, P. S., Uitterlinden, A. G., Hofman, A., Group CIw, Franco, O. H., et al. (2015). Pleiotropy among common genetic loci identified for cardiometabolic disorders and C-reactive protein. PLoS One 10:e0118859. doi: 10.1371/journal.pone.0118859

Ligthart, S., Vaez, A., Hsu, Y. H., Stolk, R., Uitterlinden, A. G., Hofman, A., et al. (2016). Bivariate genome-wide association study identifies novel pleiotropic loci for lipids and inflammation. BMC Genom. 17:443. doi: 10.1186/s12864-0162712-4

Lim, A., Zhou, J., Sinha, R. A., Singh, B. K., Ghosh, S., Lim, K. H., et al. (2016). Hepatic FTO expression is increased in NASH and its silencing attenuates palmitic acid-induced lipotoxicity. Biochem. Biophys. Res. Commun. 479, 476481. doi: 10.1016/j.bbrc.2016.09.086

Liu, J., Yue, Y., Han, D., Wang, X., Fu, Y., Zhang, L., et al. (2014). A METTL3-METTL14 complex mediates mammalian nuclear RNA N6adenosine methylation. Nat. Chem. Biol. 10, 93-95. doi: 10.1038/nchembio. 1432

Liu, J., Zhang, X., Chen, K., Cheng, Y., Liu, S., Xia, M., et al. (2019). CCR7 Chemokine Receptor-Inducible lnc-Dpf3 Restrains Dendritic Cell Migration by Inhibiting HIF-1\&\#x3b1;-Mediated Glycolysis. Immunity 50, 600-615.e. doi: 10.1016/j.immuni.2019.01.021

Liu, N., Dai, Q., Zheng, G., He, C., Parisien, M., and Pan, T. (2015). N6methyladenosine-dependent RNA structural switches regulate RNA-protein interactions. Nature 518, 560-564. doi: 10.1038/nature14234

Liu, N., Zhou, K. I., Parisien, M., Dai, Q., Diatchenko, L., and Pan, T. (2017). N6methyladenosine alters RNA structure to regulate binding of a low-complexity protein. Nucleic Acids Res. 45, 6051-6063. doi: 10.1093/nar/gkx141

Liu, Q., and Gregory, R. I. (2019). RNAmod: an integrated system for the annotation of mRNA modifications. Nucleic Acids Res. 47, W548-W555. doi: 10.1093/nar/gkz479

Lu, M., Zhang, Z., Xue, M., Zhao, B. S., Harder, O., Li, A., et al. (2020). $\mathrm{N}(6)$-methyladenosine modification enables viral RNA to escape recognition by RNA sensor RIG-I. Nat. Microbiol. 5, 584-598. doi: 10.1038/s41564-0190653-9

Lu, N., Li, X., Yu, J., Li, Y., Wang, C., Zhang, L., et al. (2018). Curcumin Attenuates Lipopolysaccharide-Induced Hepatic Lipid Metabolism Disorder by Modification of m(6) A RNA Methylation in Piglets. Lipids 53, 53-63. doi: 10.1002/lipd.12023

Maruotti, N., Corrado, A., and Cantatore, F. P. (2017). Osteoblast role in osteoarthritis pathogenesis. J. Cell. Physiol. 232, 2957-2963. doi: 10.1002/jcp. 25969

Medzhitov, R. (2008). Origin and physiological roles of inflammation. Nature 454, 428-435. doi: 10.1038/nature07201

Medzhitov, R., and Horng, T. (2009). Transcriptional control of the inflammatory response. Nat. Rev. Immunol. 9, 692-703. doi: 10.1038/nri2634

Mehta, S. L., Manhas, N., and Raghubir, R. (2007). Molecular targets in cerebral ischemia for developing novel therapeutics. Brain Res. Rev. 54, 34-66. doi: 10.1016/j.brainresrev.2006.11.003

Meyer Kate, D., Patil Deepak, P., Zhou, J., Zinoviev, A., Skabkin Maxim, A., Elemento, O., et al. (2015). 5' UTR m6A Promotes Cap-Independent Translation. Cell 163, 999-1010. doi: 10.1016/j.cell.2015.10.012

Meyer, K. D., and Jaffrey, S. R. (2017). Rethinking m6A Readers, Writers, and Erasers. Annu. Rev. Cell. Devel. Biol. 33, 319-342. doi: 10.1146/annurev-cellbio100616-060758

Meyer, K. D., Saletore, Y., Zumbo, P., Elemento, O., Mason, C. E., and Jaffrey, S. R. (2012). Comprehensive analysis of mRNA methylation reveals enrichment in 3' UTRs and near stop codons. Cell 149, 1635-1646. doi: 10.1016/j.cell.2012.05. 003

Moindrot, B., Cerase, A., Coker, H., Masui, O., Grijzenhout, A., Pintacuda, G., et al. (2015). A Pooled shRNA Screen Identifies Rbm15, Spen, and Wtap as Factors Required for Xist RNA-Mediated Silencing. Cell. Rep. 12, 562-572. doi: 10.1016/j.celrep.2015.06.053

Moscat, J., and Diaz-Meco, M. T. (2009). p62 at the crossroads of autophagy, apoptosis, and cancer. Cell 137, 1001-1004. doi: 10.1016/j.cell.2009.05.023

Müller, S., Glaß, M., Singh, A. K., Haase, J., Bley, N., Fuchs, T., et al. (2019). IGF2BP1 promotes SRF-dependent transcription in cancer in a $\mathrm{m} 6 \mathrm{~A}$ - and
miRNA-dependent manner. Nucleic Acids Res. 47, 375-390. doi: 10.1093/nar/ gky1012

Nachtergaele, S., and He, C. (2018). Chemical Modifications in the Life of an mRNA Transcript. Annu. Rev. Genet. 52, 349-372. doi: 10.1146/annurev-genet120417-031522

Nemat, K., Yadollah, S., and Mahdi, M. (2009). Chronic Inflammation and Oxidative Stress as a Major Cause of Age- Related Diseases and Cancer. Rec. Pat. Inflam. Allerg. Drug Discov. 3, 73-80. doi: 10.2174/187221309787158371

Ojeda-Ojeda, M., Murri, M., Insenser, M., and Escobar-Morreale, H. F. (2013). Mediators of low-grade chronic inflammation in polycystic ovary syndrome (PCOS). Curr. Pharmaceut. Des. 19, 5775-5791. doi: 10.2174/ 1381612811319320012

Olefsky, J. M., and Glass, C. K. (2010). Macrophages, inflammation, and insulin resistance. Annu. Rev. Physiol. 72, 219-246. doi: 10.1146/annurev-physiol021909-135846

Pacios, S., Xiao, W., Mattos, M., Lim, J., Tarapore, R. S., Alsadun, S., et al. (2015). Osteoblast Lineage Cells Play an Essential Role in Periodontal Bone Loss Through Activation of Nuclear Factor-Kappa B. Sci. Rep. 5:16694. doi: $10.1038 /$ srep 16694

Panoutsopoulou, K., Metrustry, S., Doherty, S. A., Laslett, L. L., Maciewicz, R. A., Hart, D. J., et al. (2014). The effect of FTO variation on increased osteoarthritis risk is mediated through body mass index: a Mendelian randomisation study. Ann. Rheum. Dis. 73, 2082-2086. doi: 10.1136/annrheumdis-2013-203772

Pelizzo, G., Veschi, V., Mantelli, M., Croce, S., Di Benedetto, V., D’Angelo, P., et al. (2018). Microenvironment in neuroblastoma: isolation and characterization of tumor-derived mesenchymal stromal cells. BMC Cancer 18:1176. doi: 10.1186/ s12885-018-5082-2

Pendleton, K. E., Chen, B., Liu, K., Hunter, O. V., Xie, Y., Tu, B. P., et al. (2017). The U6 snRNA m(6)A Methyltransferase METTL16 Regulates SAM Synthetase Intron Retention. Cell 169, 824-835.e. doi: 10.1016/j.cell.2017.05.003

Ping, X.-L., Sun, B.-F., Wang, L., Xiao, W., Yang, X., Wang, W.-J., et al. (2014). Mammalian WTAP is a regulatory subunit of the RNA N6-methyladenosine methyltransferase. Cell Res. 24, 177-189. doi: 10.1038/cr.2014.3

Ren, F., Shu, G., Liu, G., Liu, D., Zhou, J., Yuan, L., et al. (2014). Knockdown of p62/sequestosome 1 attenuates autophagy and inhibits colorectal cancer cell growth. Mol. Cell. Biochem. 385, 95-102. doi: 10.1007/s11010-013-1818-0

Ries, R. J., Zaccara, S., Klein, P., Olarerin-George, A., Namkoong, S., Pickering, B. F., et al. (2019). m6A enhances the phase separation potential of mRNA. Nature 571, 424-428. doi: 10.1038/s41586-019-1374-1

Rode, L., Nordestgaard, B. G., Weischer, M., and Bojesen, S. E. (2014). Increased body mass index, elevated C-reactive protein, and short telomere length. J. Clin. Endocrinol. Metabol. 99, E1671-E1675. doi: 10.1210/jc.2014-1161

Rong, Z.-X., Li, Z., He, J.-J., Liu, L.-Y., Ren, X.-X., Gao, J., et al. (2019). Downregulation of Fat Mass and Obesity Associated (FTO) Promotes the Progression of Intrahepatic Cholangiocarcinoma. Front. Oncol. 9:369. doi: 10. 3389/fonc. 2019.00369

Roundtree, I. A., Evans, M. E., Pan, T., and He, C. (2017a). Dynamic RNA Modifications in Gene Expression Regulation. Cell 169, 1187-1200. doi: 10. 1016/j.cell.2017.05.045

Roundtree, I. A., Luo, G.-Z., Zhang, Z., Wang, X., Zhou, T., Cui, Y., et al. (2017b). YTHDC1 mediates nuclear export of N(6)-methyladenosine methylated mRNAs. Elife 6:e31311. doi: 10.7554/eLife.31311

Rubio, R. M., Depledge, D. P., Bianco, C., Thompson, L., and Mohr, I. R. (2018). $\mathrm{m}(6)$ A modification enzymes shape innate responses to DNA by regulating interferon $\beta$. Genes. Dev. 32, 1472-1484. doi: 10.1101/gad.319475.118

Schöller, E., Weichmann, F., Treiber, T., Ringle, S., Treiber, N., Flatley, A., et al. (2018). Interactions, localization, and phosphorylation of the m(6)A generating METTL3-METTL14-WTAP complex. RNA 24, 499-512. doi: 10.1261/rna. 064063.117

Schwartz, S., Mumbach Maxwell, R., Jovanovic, M., Wang, T., Maciag, K., Bushkin, G. G., et al. (2014). Perturbation of m6A Writers Reveals Two Distinct Classes of mRNA Methylation at Internal and 5' Sites. Cell Rep. 8, 284-296. doi: 10. 1016/j.celrep.2014.05.048

Scott, D. L., Wolfe, F., and Huizinga, T. W. (2010). Rheumatoid arthritis. Lancet 376, 1094-1108. doi: 10.1016/s0140-6736(10)60826-4

Seruga, B., Zhang, H., Bernstein, L. J., and Tannock, I. F. (2008). Cytokines and their relationship to the symptoms and outcome of cancer. Nat. Rev. Cancer 8, 887-899. doi: 10.1038/nrc2507 
Shen, C., Zhang, Z., Xie, T., Ji, J., Xu, J., Lin, L., et al. (2019). Rhein Suppresses Lung Inflammatory Injury Induced by Human Respiratory Syncytial Virus Through Inhibiting NLRP3 Inflammasome Activation via NF- $\mathrm{B}$ Pathway in Mice. Front. Pharmacol. 10:1600. doi: 10.3389/fphar.2019.01600

Shi, H., Wang, X., Lu, Z., Zhao, B. S., Ma, H., Hsu, P. J., et al. (2017). YTHDF3 facilitates translation and decay of $\mathrm{N}(6)$-methyladenosine-modified RNA. Cell Res. 27, 315-328. doi: 10.1038/cr.2017.15

Shima, H., Matsumoto, M., Ishigami, Y., Ebina, M., Muto, A., Sato, Y., et al. (2017). S-Adenosylmethionine Synthesis Is Regulated by Selective N(6)-Adenosine Methylation and mRNA Degradation Involving METTL16 and YTHDC1. Cell Rep. 21, 3354-3363. doi: 10.1016/j.celrep.2017.11.092

Shriwas, O., Mohapatra, P., Mohanty, S., and Dash, R. (2020). The Impact of m6A RNA Modification in Therapy Resistance of Cancer: Implication in Chemotherapy, Radiotherapy, and Immunotherapy. Front. Oncol. 10:612337. doi: 10.3389/fonc.2020.612337

Singh, R., Mishra, M. K., and Aggarwal, H. (2017). Inflammation, Immunity, and Cancer. Mediat. Inflamm. 2017:6027305. doi: 10.1155/2017/6027305

Sommer, F., and Backhed, F. (2016). Know your neighbor: Microbiota and host epithelial cells interact locally to control intestinal function and physiology. BioEssays 38, 455-464. doi: 10.1002/bies.201500151

Stolte, E. H., Chadzinska, M., Przybylska, D., Flik, G., Savelkoul, H. F., and Verburg-van Kemenade, B. M. (2009). The immune response differentially regulates Hsp70 and glucocorticoid receptor expression in vitro and in vivo in common carp (Cyprinus carpio L.). Fish Shellf. Immunol. 27, 9-16. doi: 10.1016/j.fsi.2008.11.003

Sun, L., Ma, L., Zhang, H., Cao, Y., Wang, C., Hou, N., et al. (2019). Fto Deficiency Reduces Anxiety- and Depression-Like Behaviors in Mice via Alterations in Gut Microbiota. Theranostics 9, 721-733. doi: 10.7150/thno.31562

Sun, X., Luo, W., Tan, X., Li, Q., Zhao, Y., Zhong, W., et al. (2013). Increased plasma corticosterone contributes to the development of alcoholic fatty liver in mice. Am. J. Physiol. Gastr. Liver Physiol. 305, G849-G861. doi: 10.1152/ajpgi.00139. 2013

Taketo, K., Konno, M., Asai, A., Koseki, J., Toratani, M., Satoh, T., et al. (2018). The epitranscriptome m6A writer METTL3 promotes chemo- and radioresistance in pancreatic cancer cells. Int. J. Oncol. 52, 621-629. doi: 10.3892/ijo.2017.4219

Tang, L., Wei, X., Li, T., Chen, Y., Dai, Z., Lu, C., et al. (2021). Emerging Perspectives of RNA N (6)-methyladenosine (m(6)A) Modification on Immunity and Autoimmune Diseases. Front. Immunol. 12:630358. doi: 10. 3389/fimmu.2021.630358

Tu, S., Bhagat, G., Cui, G., Takaishi, S., Kurt-Jones, E. A., Rickman, B., et al. (2008). Overexpression of interleukin-1beta induces gastric inflammation and cancer and mobilizes myeloid-derived suppressor cells in mice. Cancer Cell. 14, 408-419. doi: 10.1016/j.ccr.2008.10.011

Ueda, Y., Ooshio, I., Fusamae, Y., Kitae, K., Kawaguchi, M., Jingushi, K., et al. (2017). AlkB homolog 3-mediated tRNA demethylation promotes protein synthesis in cancer cells. Sci. Rep. 7:42271. doi: 10.1038/srep42271

Varela, M. L., Mogildea, M., Moreno, I., and Lopes, A. (2018). Acute Inflammation and Metabolism. Inflammation 41, 1115-1127. doi: 10.1007/s10753-018-07391

Visvanathan, A., Patil, V., Arora, A., Hegde, A. S., Arivazhagan, A., Santosh, V., et al. (2018). Essential role of METTL3-mediated m(6)A modification in glioma stem-like cells maintenance and radioresistance. Oncogene 37, 522-533. doi: 10.1038/onc.2017.351

Wang, J., Yan, S., Lu, H., Wang, S., and Xu, D. (2019). METTL3 Attenuates LPSInduced Inflammatory Response in Macrophages via NF-. Med. Inflamm. 2019, 3120391. doi: 10.1155/2019/3120391

Wang, P., Doxtader, K. A., and Nam, Y. (2016). Structural Basis for Cooperative Function of Mettl3 and Mettl14 Methyltransferases. Mol. Cell. 63, 306-317. doi: 10.1016/j.molcel.2016.05.041

Wang, S., Chim, B., Su, Y., Khil, P., Wong, M., Wang, X., et al. (2019). Enhancement of LIN28B-induced hematopoietic reprogramming by IGF2BP3. Genes Dev. 33, 1048-1068. doi: 10.1101/gad.325100.119

Wang, X., Zhao, B. S., Roundtree, I. A., Lu, Z., Han, D., Ma, H., et al. (2015). N(6)methyladenosine Modulates Messenger RNA Translation Efficiency. Cell 161, 1388-1399. doi: 10.1016/j.cell.2015.05.014

Warda, A. S., Kretschmer, J., Hackert, P., Lenz, C., Urlaub, H., Höbartner, C., et al. (2017). Human METTL16 is a N(6)-methyladenosine (m(6)A) methyltransferase that targets pre-mRNAs and various non-coding RNAs. EMBO Rep. 18, 2004-2014. doi: 10.15252/embr.201744940

Wei, C.-M., Gershowitz, A., and Moss, B. (1975). Methylated nucleotides block $5^{\prime}$ terminus of HeLa cell messenger RNA. Cell 4, 379-386. doi: 10.1016/00928674(75)90158-0

Wei, J., Liu, F., Lu, Z., Fei, Q., Ai, Y., He, P. C., et al. (2018). Differential m(6)A, $\mathrm{m}(6) \mathrm{A}(\mathrm{m})$, and $\mathrm{m}(1) \mathrm{A}$ Demethylation Mediated by FTO in the Cell Nucleus and Cytoplasm. Mol. Cell 71, 973-985.e. doi: 10.1016/j.molcel.2018.08.011

Welsh, P., Polisecki, E., Robertson, M., Jahn, S., Buckley, B. M., de Craen, A. J., et al. (2010). Unraveling the directional link between adiposity and inflammation: a bidirectional Mendelian randomization approach. J. Clin. Endocrinol. Metabol. 95, 93-99. doi: 10.1210/jc.2009-1064

Weng, H., Huang, H., Wu, H., Qin, X., Zhao, B. S., Dong, L., et al. (2018). METTL14 Inhibits Hematopoietic Stem/Progenitor Differentiation and Promotes Leukemogenesis via mRNA m(6)A Modification. Cell. Stem Cell. 22, 191-205.e. doi: 10.1016/j.stem.2017.11.016

Whiteside, T. L. (2018). Exosome and mesenchymal stem cell cross-talk in the tumor microenvironment. Sem. Immunol. 35, 69-79. doi: 10.1016/j.smim.2017. 12.003

Winkler, R., Gillis, E., Lasman, L., Safra, M., Geula, S., Soyris, C., et al. (2019). $\mathrm{m}(6) \mathrm{A}$ modification controls the innate immune response to infection by targeting type I interferons. Nat. Immunol. 20, 173-182. doi: 10.1038/s41590018-0275-z

Wu, J., Wei, Z., Cheng, P., Qian, C., Xu, F., Yang, Y., et al. (2020). Rhein modulates host purine metabolism in intestine through gut microbiota and ameliorates experimental colitis. Theranostics 10, 10665-10679. doi: 10.7150/thno.43528

Xin, X., Wang, C., Lin, Z., Xu, J., Lu, Y., Meng, Q., et al. (2018). InflammatoryRelated P62 Triggers Malignant Transformation of Mesenchymal Stem Cells through the Cascade of CUDR-CTCF-IGFII-RAS Signaling. Mol. Ther. Nucleic Acids 11, 367-381. doi: 10.1016/j.omtn.2018.03.002

Xiong, X., Yi, C., and Peng, J. (2017). Epitranscriptomics: Toward A Better Understanding of RNA Modifications. Genom. Proteom. Bioinform. 15, 147153. doi: 10.1016/j.gpb.2017.03.003

Yang, S., Wei, J., Cui, Y. H., Park, G., Shah, P., Deng, Y., et al. (2019). m(6)A mRNA demethylase FTO regulates melanoma tumorigenicity and response to anti-PD-1 blockade. Nat. Commun. 10:2782 . doi: 10.1038/s41467-01910669-0

Yi, L., Wu, G., Guo, L., Zou, X., and Huang, P. (2020). Comprehensive Analysis of the PD-L1 and Immune Infiltrates of m(6)A RNA Methylation Regulators in Head and Neck Squamous Cell Carcinoma. Mol. Ther. Nucleic Acids 21, 299-314. doi: 10.1016/j.omtn.2020.06.001

Yu, R., Li, Q., Feng, Z., Cai, L., and Xu, Q. (2019). m6A Reader YTHDF2 Regulates LPS-Induced Inflammatory Response. Int. J. Mol. Sci. 20:1323. doi: 10.3390/ ijms 20061323

Zaccara, S., and Jaffrey, S. R. (2020). A Unified Model for the Function of YTHDF Proteins in Regulating m(6)A-Modified mRNA. Cell 181, 1582.e-1595.e. doi: 10.1016/j.cell.2020.05.012

Zhang, B., Wu, Q., Li, B., Wang, D., Wang, L., and Zhou, Y. L. (2020). $\mathrm{m}(6)$ A regulator-mediated methylation modification patterns and tumor microenvironment infiltration characterization in gastric cancer. Mol. Cancer 19:53. doi: 10.1186/s12943-020-01170-0

Zhang, Y., Gu, X., Li, D., Cai, L., and Xu, Q. (2019). METTL3 Regulates Osteoblast Differentiation and Inflammatory Response via Smad Signaling and MAPK Signaling. Int. J. Mol. Sci. 21:199. doi: 10.3390/ijms21010199

Zhang, Y., Guo, F., and Zhao, R. (2016). Hepatic expression of FTO and fatty acid metabolic genes changes in response to lipopolysaccharide with alterations in m(6)A modification of relevant mRNAs in the chicken. Br. Poultry Sci. 57, 628-635. doi: 10.1080/00071668.2016.1201199

Zhao, H., Lv, Y., Li, L., and Chen, Z. J. (2016). Genetic Studies on Polycystic Ovary Syndrome. Best Practi. Res. Clin. Obstetr. Gynaecol. 37, 56-65. doi: 10.1016/j. bpobgyn.2016.04.002

Zhao, W., Qi, X., Liu, L., Ma, S., Liu, J., and Wu, J. (2020). Epigenetic Regulation of m(6)A Modifications in Human Cancer. Mol. Ther. Nucleic Acids 19, 405-412. doi: 10.1016/j.omtn.2019.11.022

Zheng, G., Dahl, J. A., Niu, Y., Fedorcsak, P., Huang, C.-M., Li, C. J., et al. (2013). ALKBH5 is a mammalian RNA demethylase that impacts RNA metabolism and mouse fertility. Mol. Cell. 49, 18-29. doi: 10.1016/j.molcel.2012.10.015 
Zhou, J., Wan, J., Gao, X., Zhang, X., Jaffrey, S. R., and Qian, S.-B. (2015). Dynamic $\mathrm{m}(6) \mathrm{A}$ mRNA methylation directs translational control of heat shock response. Nature 526, 591-594. doi: 10.1038/nature15377

Zhou, Y., Hambly, B. D., and McLachlan, C. S. F. T. O. (2017). associations with obesity and telomere length. J. Biomed. Sci. 24:65. doi: 10.1186/s12929-0170372-6

Zimmermann, E., Skogstrand, K., Hougaard, D. M., Astrup, A., Hansen, T., Pedersen, O., et al. (2011). Influences of the common FTO rs9939609 variant on inflammatory markers throughout a broad range of body mass index. PLoS One 6:e15958. doi: 10.1371/journal.pone.001 5958

Zong, X., Zhao, J., Wang, H., Lu, Z., Wang, F., Du, H., et al. (2019). Mettl3 Deficiency Sustains Long-Chain Fatty Acid Absorption through Suppressing
Traf6-Dependent Inflammation Response. J. Immunol. 202, 567-578. doi: 10. 4049/jimmunol.1801151

Conflict of Interest: The authors declare that the research was conducted in the absence of any commercial or financial relationships that could be construed as a potential conflict of interest.

Copyright (c) 2021 Luo, Xu and Sun. This is an open-access article distributed under the terms of the Creative Commons Attribution License (CC BY). The use, distribution or reproduction in other forums is permitted, provided the original author(s) and the copyright owner(s) are credited and that the original publication in this journal is cited, in accordance with accepted academic practice. No use, distribution or reproduction is permitted which does not comply with these terms. 